European journal of American studies

Special Issue: Video Games and/in American Studies:

Politics, Popular Culture, and Populism

\title{
Rockstar Games, Red Dead Redemption, and Narratives of "Progress"
}

\section{Esther Wright}

\section{(2) OpenEdition}

\section{Journals}

Electronic version

URL: https://journals.openedition.org/ejas/17300

DOI: $10.4000 /$ ejas. 17300

ISSN: 1991-9336

Publisher

European Association for American Studies

Electronic reference

Esther Wright, "Rockstar Games, Red Dead Redemption, and Narratives of "Progress"', European journal of American studies [Online], 16-3 | 2021, Online since 09 September 2021, connection on 17

September 2021. URL: http://journals.openedition.org/ejas/17300 ; DOI: https://doi.org/10.4000/ejas 17300

This text was automatically generated on 17 September 2021

Creative Commons License 


\title{
Rockstar Games, Red Dead Redemption, and Narratives of "Progress"
}

\author{
Esther Wright
}

\section{Introduction}

More and more civilization, what a damn mess we're making of things.

- Arthur Morgan, Red Dead Redemption 2 (2018)

In October 2019, almost a year after it was first released, Rockstar Games announced that Red Dead Redemption 2 (RDR2) was being released for PC (@RockstarGames). Hugely anticipated by Rockstar fans, the news was soon accompanied by an announcement trailer designed to showcase the superior experience players could expect from this platform, compared to console versions of the game (e.g., Rockstar Games, "Red Dead Redemption 2 for PC"). Echoing this, news coverage around the release of this "enhanced" version of the game focused on technical specifications, how the improved quality enriched Rockstar's remediated Western game world, and thus, how much better this iteration of the game would look and feel to play (e.g., Weber; McKeand; Sarkar; Ryan; Freeman; Senior).

This rerelease to PC was promoted (and received) as the achievement of a certain kind of "progress"-originating from both the critical industry that surrounds video games and Rockstar themselves-in keeping with Rockstar's reputation as a developer. That is, Rockstar have long crafted and maintained an identity as industry leaders that are constantly pushing the boundaries of the games industry, celebrated and rewarded with various accolades and financial success. A Rockstar-generated discourse of (games industry) "progress" is therefore also key to both the company's brand identity and the promotional surround of their games beyond the Red Dead franchise.

However, discussion of the ways this version would better the experience of RDR2 was only one level at which a narrative of "progress" continued to be centralized in the discourse around the game. Dialogue from RDR2's playable protagonist Arthur Morgan 
was used in the aforementioned trailer as accompanying voiceover, narrating sweeping shots of the game's Western landscapes. The particular dialogue fragments chosen to accompany these shots were telling: "We're a long way East of land we know, far from real open country. More and more civilization, what a damn mess we're making of things" (Rockstar Games, "Red Dead Redemption 2 PC Trailer"). Implicitly historical ideas about "progress" and "civilization" are central to Rockstar's critically acclaimed and fan-beloved Westerns. Both RDR2 and the franchise's previous installment, Red Dead Redemption (2010; RDR), are set at the turn of the twentieth century and structure their deeply historical stories and gameplay options around a lament for the passing of an imagined age of outlaws, the "taming" of the "Wild West," and the loss of open, free Western space as a means of survival for white, male outlaws.

The promotion of the Red Dead franchise included numerous claims, in no uncertain terms, about the series' attempt at offering a historically "authentic" experience of this period in American history. Moreover, another key aspect of Rockstar's brand identity is their "reputation for iconoclastic, satirical, and critique-oriented scenarios" (Murray, On Video Games 193-95). In the context of the Red Dead franchise, this manifests in games that seek to offer critique of American "progress," defined in terms of capitalist excess, the establishment, and policing of law and order; that is, the very things that white male outlaws like Arthur Morgan and John Marston are attempting to escape.

Yet terms like "progress" and "civilization" have a long and troubled history, not only in popular culture more broadly but also in American Studies and Western historiography. In a review of Theodore Roosevelt's multi-volume The Winning of the West (1899), the ur-historian of the American West Frederick Jackson Turner wrote that "American history needs a connected and unified account of the progress of civilization across the continent" (cited in Trachtenberg 13). A precursor to the now-infamous "Frontier Thesis," this apt phrase nonetheless sums up the purpose of both Roosevelt's works and Turner's address to the American Historical Association at the Chicago World Fair in 1893. At a "critical juncture" in late-nineteenth-century America, amidst the rise of cities, immigration, labor disputes, corporate power, and economic uncertainty, both aimed to define the space of "the West" and its occupation as central to American history and national identity, while providing an overarching narrative and justification for white settlers who had moved Westward in previous decades: one that combined religious "mission" with notions of economic and social "progress" (Trachtenberg 13). The idea of the American West as a "national safety valve" (Kuenz 100), a "symbol of freedom" and an "escape from the conditions of modern industrial society" (Tompkins 4) could hardly better describe the thematic touchstones and rationale for Rockstar's Western franchise, as has been previously argued through textual analysis of RDR (Humphreys).

Yet the centrality of Turner and his conception of the Frontier to American history has been necessarily challenged in recent decades, not least for the way that his Thesis made "claims based on a decidedly partial experience" (Trachtenberg 17). As Patricia Nelson Limerick wrote, "Turner was, to put it mildly, ethnocentric and nationalistic" (21). His "Frontier" described not a geographical place that turned Europeans into Americans but a process in which "civilization" conquered "savagery" before moving further West (Limerick 26). Still, the "F-Word" as a pervasive, useful myth has remained central to American history, culture, and identity (cf. Slotkin). The "stars of 
his story"-and most of the stories told ever since-were "English-speaking white men," with women and people of other racial and ethnic identities marginalized or rendered "invisible" to varying degrees (Limerick 21).

This article therefore explores the way that notions of "progress" are utilized by Rockstar on three levels: 1) in maintaining Rockstar's image as a developer-brand, 2) within the Red Dead franchise's promotional surround, and 3) in textual content of the games themselves. Notions of "taming the Frontier" work in complementary ways for both Rockstar and Red Dead, creating a paratextual narrative of industrial progress, development, and innovation that adds value to their products, while feeding on and perpetuating wider popular myths and understandings of Western history, deeply encoded as they are with particular ideologies. But there are consequences to adopting this discourse, and these terms, without a full appreciation or examination of their ideological underpinnings or historical context: In particular, it will be argued that this practice undercuts the company's attempt to offer "critique" of late-nineteenth- and early-twentieth-century US modernization and corporatization and the implicitly racist inflections of the other kind of "Frontier" narrative the games satirically, knowingly incorporate.

In Digital Play, Kline, Dyer-Witheford, and de Peuter wrote that

[t] he games industry, like the rest of popular culture, has learned that irony is a nolose gambit, a "have your cake and eat it too" strategy whose simultaneous affirmation/negation structure can give the appearance of social critique and retract it in the same moment-thereby letting everything stay just as it is while allowing practitioners to feel safely above it all even as they sink more deeply in. (277)

Indeed, Rockstar's games in particular have been criticized for this. Grand Theft Auto has been read as a "cynical" franchise that "simultaneously satirizes, indulges in, and normalizes individual hyperpossessiveness, racialized stereotypes, and neoliberal violence in a self-cancellation that allows these elements to remain intact, a structure that is, in a very precise way, conservative" (Dyer-Witheford and De Peuter 181). Similarly, this article will discuss the ways in which Rockstar have continued-like other video game brands and developers (see Fuchs et al.)-to offer critique of and implicitly rely on capitalist logic, white supremacy, and imperialism in creating and selling both video games and developer brand values. It asks how, in turn, we might judge the critical yet contradictory image of the past they offer players, ultimately arguing that we should question the value of any criticism that merely scratches the surface of deep-rooted, structural violence, while elsewhere profiting from the discourses historically associated with it. By analyzing the specifics of where and when narratives of progress are used to sell these games and tell their stories, we find what appears to be the inherently contradictory incorporation of and reliance on themes that Rockstar appear desperate to critique: especially the violence of progress and its effect on individuals' lives.

\section{The Rockstar Brand and Open-World Development}

"Outlaws for Life" was a slogan emblazoned on merchandise, posters, and various other promotional materials for RDR2-and even, for a time, on a banner above the entrance of Rockstar North in Edinburgh. It referred, arguably, not only to the central protagonist(s) of the franchise but also to the way Rockstar have long tried to engineer 
their brand identity: that of rebellious outsider, or games industry "problem child" (Dyer-Witheford and De Peuter 155; Wright, Rockstar Games 45-48). Yet over the past two decades, Rockstar have also claimed the status of games industry leader, particularly in open-world game development. These two notions often intersect to underpin claims that through Rockstar's games, the company's unconventional outlook and commitment to the medium, the open-world genre evolves and progresses: creating bigger and, ultimately, "better" products. This narrative of "progress" runs consistently through the promotional and official discourse that accompanies the release of Rockstar titles. Press releases published by Rockstar's parent company TakeTwo Interactive consistently reference Rockstar's "reputation as creators of complex living worlds," largely "cemented" by and through GTA (e.g., Take-Two Interactive Software). The continuing success of GTA Online has been aptly described as "worldconquering" (Kelly), bringing to mind notions of dominance and imperialism that are hardly misaligned with Rockstar's own official communication, nor the broader critiques of the Westernized, colonial images and ideology of video games like Rockstar's that encourage exploration and mastering of digital space (Lammes; Mukherjee; Mukherjee and Hammar; Murray, "Horizons Already Here" 44-45). Moreover, some promotional blogs explicitly work to emphasize that Rockstar's games are part of a "new frontier" of game development (e.g., Rockstar Games, "L.A. Noire Honored"), using "the F-Word" for their own promotional ends.

Reviews and promotion for the Red Dead franchise are similarly concerned with noting Rockstar's progress in developing their open-world environment and gameplay options within it. Reviews of both instalments written by Nick Cowen for The Telegraph in 2009 and 2018, respectively, both sought to portray Rockstar as the "standard-bearers of the open world" (Cowen, "Red Dead Redemption"; Cowen, "Red Dead Redemption 2"). Indeed, when RDR2 was about to be released in late-2018, articles reported that Rockstar had opted to do away with the term "open-world," in favor of adopting the moniker "Rockstar World" (McCaffrey).

The aspect of Rockstar's brand identity that perpetuates this kind of narrative can be contextualized within a games industry obsessed with "progress," and the way game history has, until recently, been written. Laine Nooney writes that "[i]t should be no revelation whatsoever to state that the history of videogames is a patrilineal chronicle, a forward-marching timeline punctuated by sacred litanies of 'founding fathers', 'hacker heroes', and 'game gods"' (Nooney). Much academic work has been recently undertaken to "[counter] the digi-Whiggish and determinist approaches" to writing the history of video games, which seemed the inevitable consequence of the industry's own obsessive focus on the "improvements" and evolution between platforms and technologies, and the way both memories and material about the industry has been preserved (Litherland 3; see also Kerr; Therrien). Recontextualizing Walter Benjamin's notion of the "barbarism" of the practice of writing histories, Soraya Murray recently described the "violence that has shaped the ground of game histories": that is, "its continued embrace of specific notions of innovation, genius, and a future orientation. It is still largely a history focused on the technological, propelled by a notion of advancement and a sense of logical unfolding, always toward some ultimate and perfected outcome on the horizon" (Murray, "Triumphal Procession"). Of these challenges, Carl Therrien questioned "[h]ow is one to avoid a progress-laden teleological discourse when faced with an object that seems to be defined by its constant evolution?" (10). As Murray articulates, "this is a fairy tale of technological 
progress; it is science fiction, not history," noting that histories of games "are sited within, and constituted by, the larger goings-on of society," and "happen in a larger ecosystem populated by a whole lot of unnamed others, toiling along anonymously in the services of those Great Works of History that eventually crush them" (Murray, “Triumphal Procession").

In this context, the cautions of game historians echo those of historians of the American West like Limerick, equally preoccupied with the violence of perpetuating narratives of "progress" and conquest when writing about the past, continually ignoring those who were long marginalized in popular memory and historical record. A relentless obsession with the quality and innovation of open-world game development risks losing sight of the ideological resonances that both "progress" and the so-called open-ness of "the West" contain, specifically in terms of the utility of the Frontier myth for American history and national identity (Tompkins 4).

\section{The "True West" and an "Evolving" America}

Like histories written about video games, the histories that are written in games often (re)constitute narratives of progress. They usually-implicitly or explicitly-claim to offer players access to a reconstruction of the advancement of historical time, modernization, and similar kinds of industrial or technological progress (see, for example, Chapman 149-50). Thus, despite their radical potential for representing other kinds of narratives and experiences, historical video games often appear to be "built around organizing principles" that inevitably reflect a "historiographic status quo" (Uricchio 335-36).

For Rockstar, reflecting and commenting on the binary division between "civilization" and "savagery"-the modernizing "progress" of American history in contrast to the "freedom" the West offered-is central to their attempt at creating Westerns that players and critics perceive as "authentic" and representative of American history. For both $R D R$ and $R D R 2$, Rockstar created a wide paratextual network of content players could engage with before playing the games for themselves (see also Wright, "Marketing Authenticity"). Much of this content positioned Rockstar in a pedagogical role, attempting to not only preload potential players with information about the game's historical "truths" but to negotiate and manage expectations for the game's representation of the past: an overt attempt to create "a discourse of historical authenticity" (Wright, Rockstar Games 70-90).

Between January and September 2010, a series of blog posts under the heading "The True West - History that Helped Inspire Red Dead Redemption" were published to the Newswire section of the official Rockstar website, a paratextual site of direct companyto-fan communication. Even more explicitly than the aforementioned trailer for RDR2, these posts positioned Rockstar in the role of "developer-historian" (Chapman), committed to maintaining certain standards of research and ensuring the "authenticity" of player experience. Promotional sources such as these posts are key in analyzing the developer's particular interpretation of history. Aside from commodifying the research undertaken by Rockstar, the first promotional blog post published in this series directly historicizes the world RDR portrays. Offering Rockstar's own narrative of "[t]he turn of the $20^{\text {th }}$ century," the post cites technological 
developments and industrialization as harbingers of the "death of the old, wild Western frontier of the 1800's" (Rockstar Games, "Part One: Frank James").

Enriching a discourse dispersed among other promotional materials, discussions of progress, transition, and development run core to this series of blog posts: highlighting developments made in the production of weaponry by American inventors and the modernization of weapons in the years leading up to the First World War (Rockstar Games, "Western Weaponry"); the invention of communications devices, such as the telephone, that "changed the way Americans lived" (Rockstar Games, "New Inventions"); innovations in patent medicines; and the recreational or medicinal uses of drugs and alcohol (Rockstar Games, "Patent Medicines, Drink and Drugs"). Rockstar drew players' attention to their labor in creating "authentic" brands and advertisements in RDR: a Newswire post entitled "The Brands of Red Dead Redemption" showcased a range of advertisements and logos for fictionalized, yet era-appropriate brands that would appear in the game world, which players were informed was a sign that the game "stays true" to the particular period in US history being represented: namely, "the dawn of the consumer and commercial age in America" (Rockstar Games, "The Brands"). Consistently emphasized is that this was "a period of rapid and tumultuous change" (e.g., Rockstar Games, "New Inventions”; Rockstar Games, "Patent Medicines").

This continued in the promotion of $R D R 2$, a prequel with a story set twelve years before in 1899. From the outset, promotional materials publicized the game's engagement with and representation of Western history and prefigured the narrative of progress that would inextricably underpin it. The first of a series of official "gameplay videos" was released on $9^{\text {th }}$ August 2018, using a non-diegetic voiceover to introduce core gameplay elements players could expect. It also aimed to historically contextualize the game world and narrative that players would pursue:

In the late 1800s, America was evolving, on its way to becoming the most powerful country in the world. New immigrants arrived, thriving outposts became towns, and civilization was spreading rapidly into the huge, wild and lawless frontier. With Red Dead Redemption 2, Rockstar Games aims to create a living world that's not simply open, but deeper, more interactive and detailed than ever ... combining action, storytelling ... and gameplay in new ways, as you live, ride and fight to survive as an outlaw in a notorious gang .... The game is an attempt to capture this pivotal moment when the age of outlaws was ending and the modern world was born. (Rockstar Games, "Red Dead Redemption 2: Official Gameplay Video")

The language used throughout positions RDR2's Western spaces as a world of stark opposites on the cusp of being transformed from "wild" to "tamed," from "old" to "new." Threaded throughout the trailer are further characterizations that consistently portray contrasts between "rugged" and "modernizing" spaces: developing outposts and towns against the harshness of mountain trails and "untamed swamplands." Arthur Morgan, the playable protagonist, is characterized as the Van Der Linde gang's most trusted gunslinger, while describing the gang-as the quasi-family unit the player will need to support and protect-as "on the run from the pressures of civilized life." Such is the extent to which this discourse of "savagery" and "civilization"-progress and modernization versus the free, open spaces of "the West"-underpins Rockstar's attempt to generate interest in and expectations for their game. These are all statements that offer a specific historical analysis of the past and, as such, demand close attention. 
In exploring the "Incorporation of America" in the Gilded Age, Alan Trachtenberg wrote that "civilization" was wrought through a combination of violence and increasing corporatization of life (17). It is indeed this kind of corporatization that Dutch and his followers seek to resist (usually through violence) in RDR2, and that John Marston and his family are trying to flee (albeit naïvely) in RDR. Both narrative and gameplay are structured around this core conceit in both games. Moreover, Rockstar's growth and financial success as a brand within the games industry has also resulted in a company that increasingly makes games that are bigger, more "open," more concerned with exploration and the illusion of "freedom" and "choice" and able to do so in more technologically impressive and "immersive" ways: making claims that the world is "real" or "alive" and responds to the players' every action and decision in a natural way (e.g., Coldewey; Hooton; Webster; MacDonald). RDR2 encapsulated the result of this development history and brand expectations, and Red Dead Online explicitly encourages players to become whatever kind of Westerner-Bounty Hunter, Trader, Trapper, for example-that satisfies their desire to exist in this virtual West.

This impression of the history of Westward expansion as a space that provided a "safety valve" for (white) Americans wishing to escape the pressures of modernizing life (Kuenz; Tompkins; Humphreys) complements the digital Frontier and narrative that games like RDR and RDR2 depict, while also complementing Rockstar's wider brand narrative: of the company pushing the "frontiers" of open-world game development. But this impression of the colonizing of the American West bears little resemblance to historical reality. While the Homestead Act in 1862 was designed to encourage the settlement of Western land by the Jeffersonian ideal of the "yeoman farmer," only ten percent of land between 1860 and 1900 was settled by individual homesteaders, the rest by rising private companies or the States themselves (Trachtenberg 22, citing Shannon; see also Limerick 23). The premium placed on the Van Der Linde gang, and later, the Marston family's pursuit of this free, unburdened, "honest" homesteader life in many ways then reflects the futility or lost promise of this ideal, and of the mythical Western land in which it was supposed to be a possibility. That is, while both franchise installments include extended sections of the ludonarrative that require the player to undertake domestic actions, ${ }^{1}$ the outcome is always unavoidably tragic, denying the opportunity to live the ideal "Western" life.

But it is difficult to perceive this critique as anything more than a superficial repurposing of themes long espoused by canonical, so-called "revisionist" Westernsfrom The Wild Bunch (1969) to Unforgiven (1992) and beyond-more brutal and pessimistic in outlook and tone when dealing with the male outlaw's relationship with modernizing America. This is especially apparent when exploring the ways in which some promotional materials reference the rise of the corporate, and the resulting evolution of American society and business, to sell the games' historiographical engagement. A number of faux-historical advertisements were created and featured on the official website for RDR2, made to look like the pages of the Wheeler and Rawson Co. mail-order catalogue that players would use as an interface to buy provisions, weapons, and clothing in the game. One advert described the Cattleman Revolver as "the gateway to the riches of the frontier. Whether cattleman, lawman, trapper or aspiring tailor, there is no better revolver to have at your side when heading west into the land of milk and honey." Overt gestures to the player-as-conqueror-heading-West aside, the advert notes: "A side-arm for many years of the US Army, it is manufactured at a factory we own and control in Worcester, Mass. It is made by skilled laborers who work tireless 
hours each week and on the weekend for little pay in order to bring you the finest revolver in the field today" (Rockstar Games, "Weaponry"). It is ironic that such a tongue-in-cheek statement about working conditions in industrializing America was incorporated into the promotional surround of a game developed by a company firmly at the epicenter of a capitalist global games industry with its own storied history of labor issues and controversies around "crunch" culture (see Schreier). But it is unlikely that this is an explicit attempt at self-reflexive acknowledgement and more so another example of the industry's desire to "have their cake and eat it too" in their use of irony: making a critical statement about the evils of "civilization" and labor exploitation "in the past" while being complicit in similar practices endemic to the industry they are leaders of-and expecting workers to crunch in order to facilitate the creation of a game exhalating the "freedom" and promise of "the West."

This is one of several indications that Rockstar's critique of American "civilization" is selective, to say the least. At best, it suggests a lack of critical engagement with and understanding of the colonialist, implicitly white supremacist underpinnings of the civilization/savagery binary and more opaque terms like "progress" that decades of historiographical work have been attempting to grapple with to complicate the broader, mythic dichotomies often associated with the American West. Granted, we might argue that it is unrealistic to expect a video game to prioritize accounting for such nuanced historiographical debate. Yet if the games are to be excused from certain standards of historical practice, why bother to repeatedly make claims about the games' relationship to historical "truth" in the first place?

Moreover, both games' textual mediation of the turn of the twentieth century as a claimed-pivotal moment in Western history are predicated on this binary opposition that, as mentioned, ran central to many of the post-1960s Western films that Rockstar cite as their central influence elsewhere in their promotional surround (e.g., Rockstar Games, "The Wild Bunch"; Wright, Rockstar Games 102-16). As playable protagonists, John Marston and Arthur Morgan inhabit the imagined liminal space between a world that is modernizing and a world in which an outlaw could escape and live free, and the games' narrative and gameplay affordances are entirely structured around their occupation of this space. But as noted above, this is a mythical construction of Western history which is resultantly entirely racialized and gendered to exclude anyone that is not a particular kind of man of action; and indeed, a white man of action. It shores up concepts like the Turnerian notion of the Frontier's "closure" that are entirely rooted in white supremacy, Manifest Destiny, and the eradication of Indigenous peoples and histories.

It would be one thing if this was merely a kind of ideological hangover present within the game that historians of the US are more likely to read into-after all, it is not just Rockstar's responsibility to overturn the myths established by over a hundred years of Westerns and Western historiography which privileged the stories of white men. But within the games themselves and some of the promotional materials created to sell them, Rockstar tried to deal explicitly with the complex history of Native American removal and genocide, and with scientifically racist understandings that often served as a justification for these processes of ethnic cleansing and violence against people of color. Making direct interventions into these discourses with their games, and making authenticity claims about their historical narratives, therefore requires us to consider exactly what representation of the past they offer. 


\section{“It's 'reverse Integration'...or 'regressive acculturation'...; or, "Eugenics for Beginners"}

If the foundations of the Red Dead franchise are largely built on how "progress" and "civilization" are making "a damn mess" of things for the (mostly) white protagonists and major characters, what are the consequences for the representation of those who have so often served as the antithesis to settler colonial "progress"? Some promotional materials for RDR made explicit reference to the violent consequences of American colonialism for Indigenous peoples. The abovementioned Newswire blog posts included acknowledgement that "the Native American population was decimated and relegated to military-style reservations," while "the American people extended the nation's boundaries as far as California, Oregon and Alaska" (Rockstar Games, "Part One: Frank James"). As a historical statement, it is not unlike Limerick's assessment that the Frontier was actually a process of conquest by white American people at the expense of others.

Yet Jodie Byrd notes that even the first two words of the franchise's title-"Red dead"betray the lingering aftereffects of genocidal racism and colonization (345). Moreover, while RDR and its successor "supposedly offers a critique of the Western genre," major themes, and historical associations, it also "simultaneously ... fetishizes genre at the site of the Indian absent presence" (344). Thus, while occupying the hardly revolutionary position that Native extermination was "bad," this is not really the games' main focus.

Indeed, Native American characters are only included in the narratives of RDR and RDR2 insofar as they offer a convenient device through which white outlaws like Dutch Van Der Linde, Marston, and Morgan are positioned as oppositional to "the Law" and those looking to "civilize" the West. That is, the value of Native Americans to the story Rockstar sought to tell about Westward expansion is directly proportional to their otherness, and to the white outlaw's ability to reinforce their otherness through association with them. This is, in itself, a disingenuous oversimplification and (mis)use of the complexities of Native American genocide and "Indian Removal" in the nineteenth century. Moreover, the deliberate selection of a very particular time period within which to set this game world-between the very cusp of the twentieth century and the end of its first decade-confines any and all Native American characters to Reservations. In RDR, the Reservation at Cochinay cannot be visited by the player, except during and after the final third act missions ("And You Will Know the Truth"/"And the Truth Will Set You Free") in which the player, as Marston, must attack the Reservation (and its all-male inhabitants) in pursuit of Dutch, who has enlisted them to his cause. Yet while Marston is never himself depicted as sharing in the other characters' overt racism, this means little given the fact that the final mission in RDR's third act requires the player to storm the Reservation with the US Army and federal agents. Pursuing Dutch necessitates wiping out every last man on the Reservation as a predetermined mission objective that requires completion. Marston is positioned alongside other white men in a non-white space and is implicated in what is a micro-scale recreation of racist, genocidal violence. Indeed, this is not the only time a Rockstar title has been critiqued for depicting spaces occupied by black, brown, or people of color as "exotic" and/or "dangerous," utilizing them as "a backdrop for a 
white male protagonist to reconnect to a sense of purpose through extreme and cathartic violence against" those people (Murray, On Video Games 197)

By contrast, in RDR2, the Wapiti Reservation is a game space that largely only includes the old and infirm. ${ }^{3}$ A very particular explanation is offered for this through a conversation with Eagle Flies, the son of chief Rains Falls, while the player is riding to a mission location: "All the young have been taken from our Reservation, shipped off to reform schools. Many women too." 4 Those who remain are old, "weak and sick," and rely on the benevolence of a "good" army Captain who tries to provide them with medicine and care. On the one hand, the emptiness or inaccessibility of these othered spaces-that they are either empty or merely populated by the old and dying-misses any and all opportunity to more fully represent lived experiences on Reservations. It also perpetuates notions long reinforced through popular culture, US government policy, and "scientific" scholarship that they are increasingly "vanishing," if they have not vanished already, and that such a fate was in itself tragic but inevitable (Dippie). Yet more troubling is the fact that the suffering and threatened extinction faced by Native Americans is consistently aligned with the threatened extinction of white outlaws. When (and only when) it suits them, Dutch and the gang elect to "play Indian" as a way of negotiating their identity, paralleling the way that white Americansparticularly white American men-have long adopted the look or practices of Native Americans to negotiate their individual (or national) identity (Deloria).

Beyond the confines of the Reservation, in RDR the inclusion of the only Native American character of any significance, Nastas, serves another purpose of more immediate relevance to this article: the "progress" of scientific inquiry, and more particularly, the progress of race science. Raised on the Cochinay Reservation, Nastas is eloquently critical of government policy and the actions of white Americans against Indigenous communities, evidenced by his dialogue with other characters in both cutscenes and wider gameplay. For the majority of the time that his character is narratively significant, Nastas is played off against disgraced former Yale professor Harold MacDougal, who has been employed by the government as a liaison between the agents and local Indigenous characters like Nastas. In the first cutscene for the mission "At Home with Dutch," Marston meets MacDougal while he is at work in his hotel room, trying to prove a "theory of natural population characteristics" and to define the "savage spirit." After enquiring after Marston's racial heritage (questioning his "Nordic stock," based on physical appearance), MacDougal explains his shock upon discovering that the blood of Native and white Americans appears the same under a microscope. He feels that he is doing his "bit for humanity" in studying Native Americans, and through studying Dutch he hopes to learn about "[a] white man living among natives. A civilized mind turned savage." He seeks to decide on the appropriate academic terminology for his anthropological "discovery": "It's 'reverse Integration'... or 'regressive acculturation." Moreover, when speaking directly to Nastas, MacDougal is condescending, speaks slowly using hand signals, and claims the only way to communicate with "these savages" is in metaphors: "I know we cannot see the stars, but still my heart is pure, and we meet as equals!" While these attitudes are hyperbolized as part of Rockstar's attempt at irony, they are largely played for laughs in the juxtaposition between MacDougal's "scientific" racism and Nastas's rationality: relying on the player to infer that this is the usual discourse of civilization versus savagery playing out in reverse, an example of anachronistic values. Yet despite what Matt Margini terms RDR's “obvious distaste" for MacDougal, the game's otherwise 
"studious adherence to a history of Hollywood whitewashing" (103), and its consistent centering of John Marston, makes it difficult to read this as meaningful critique. Ultimately, this interaction makes a reductive joke of the real history of race science, the experiments white men performed on black and brown bodies, and the legacy of these racist misconceptions that continue to be felt in modern science and medicine (Saini; Villarosa).

It would be overly simplistic to state that Rockstar are not critical of the way that this civilization versus savagery discourse is used to persecute people. Moreover, Rockstar's are not the only video games to rely heavily on this boundary and its connection to America's founding myths (Schoppmeier). Like all Rockstar titles, both RDR games suggest an awareness about the way they engage in representations of American history, which is usually exhibited in the non-optional conversations that the playable protagonists engage in or in cutscene dialogue that is equally predefined and immutable. In both games, the representatives of "Law and Order"-Federal Agent Ross, Pinkerton Agent Milton, and sadistic US Army Colonel Favours, respectively-are created as stand-ins for US government policy in general, and for its direct effects on both the outlaws at the center of the narratives and the Indigenous peoples that exist on the narrative and gameplay margins. In RDR, during the mission "And the Truth Will Set You Free," Ross tells Marston "Let's just say [the Governor of New Austin] has a vested interest in cleaning the filth out of this region. I don't think our old friend Dutch realizes what a great favor he has done us inciting all this hate among the natives." Along very similar lines in RDR2, a conversation between Milton and Dutch, in a cutscene before the fourth act of the game begins, echoes this sentiment:

Agent Milton: This is a civilized land now. We didn't kill all those savages only for the likes of you to act like human dignity, and basic decency was outmoded or not yet invented. This thing, it's done.

Dutch: This place...ain't no such thing as civilized. It's man so in love with greed he has forgotten himself and found only appetites.

These sorts of exchanges are particularly emblematic of the way Rockstar's games interrogate and offer critique on America's particular ills. Yet incorporating these sorts of gestures to much broader issues in American Frontier history is hardly a progressive challenge to the presumed player's conception of Western history; this is "hardly a radical revision to the Western to suggest that Anglos did horrible things to Native American nations who did nothing to provoke them" (Keller 47). In this sense, it is hard to read these "critiques" as anything deeper than a disingenuous attempt to make the cause of the white outlaws (always at the center of these stories) seem more righteous, or "satirizing" American history by co-opting actual histories of genocide, because the true "enemy" is the emergence of law and its resulting imposition on white men like Marston and Dutch-who are the victims at the center, not the stories of Native Americans at the game's historically appropriate peripheries as a box-checking exercise toward providing greater historical texture and "authenticity."

In the end, these games elicit the greatest sympathy for, and spend the most time detailing the stories of, the resolutely white male protagonists and their associates as victims, not the Indigenous populations the game so often gleefully reminds us are at odds with "civilization," nor any other non-white character who, in historical reality, would have experienced far worse violent opposition to their existence. This is a false equivalence that-intentionally or not-threatens to erase or overlook an actual lived history of intellectually, philosophically, and politically sanctioned racism that ensured 
that Indigenous peoples were wiped out; something that video games in general have an issue with (see, for example, Almahr). Presenting the slaughter and forcible removal of Native Americans as something that is more or less broad and intangible that happened in "the past," it confines mistreatment and discrimination of Indigenous Americans to history, not as an ongoing site of tension in twentieth- and twenty-firstcentury American society and politics.

In Red Dead Redemption 2's city of Saint Denis-a representation of all that is wrong with American modernity and "progress"-a number of NPCs stand on street corners waiting to give out or sell the player pamphlets or books. If you choose to take one of these pamphlets-"Eugenics for Beginners," by Professor Norris Forsythe-the man handing them out will begin to tell the player, through an interaction with Arthur Morgan, that the white race is under attack and that he can explain the difference between the white race and other races with "real science." Morgan's pre-scripted response to this is that he has friends of all different racial backgrounds-an oftrepeated response to suggestions that a person is racist-and that he's known "good," "bad," and "dumb white people." It is a response that suggests he believes in equality of humans beyond superficial racial distinctions, akin to the similarly often repeated suggestion that a person "doesn't see race," which works to hide white privilege, racial bias, and structural racism (Blake).

The belief held by some on the far right that the white race is "under attack" has never been an uncommon sentiment in America and has increasingly become part of mainstream discourse over the last decade, and especially within the context of the Trump Administration (e.g., Serwer). ${ }^{5}$ Perhaps this is something that the game is trying, in its own way, to reflect and critique. But Morgan's “I don't see color" response and the brief duration of the encounter hardly provides enough space for critical reflection. The man is quickly emasculated by Morgan's threats of physical violence and dispensed of by running away screaming-not because of his racist beliefs but because he dared to call Morgan "dumb."

Should the player choose to take it, the description of the pamphlet when players retrieve it from Morgan's satchel menu states that it is "[a] racist, idiotic eugenics handbill from Norris Forsythe." While this seems like a presentist perspective on real beliefs held by many in the past (and present), it is arguably not a radical stance for a contemporary, "critical" game developer to include on historic racism in America. Like the characterization of MacDougal in RDR, race science and eugenics are largely characterized as something "idiotic" and "of the past." As with the inclusion of other optional gameplay and narrative elements in $R D R 2,{ }^{6}$ it shies away from truly representing real, pervasive, structural racism and beliefs which never truly died out (Saini), in favor of only individual "bad" racists-a tactic that aligns the game more with US Conservatives, old and new (Anderson 100), than with an inclusive retelling of US history. Moreover, Forsythe's peddling of his racist wares to Morgan is one of several such encounters the player can have in Saint Denis, as mentioned above. Others include a woman demanding female suffrage and a proto-entrepreneur selling get-richquick schemes. Thus, the satirical ridiculousness of all three, and the way Morgan is able to interact with these NPCs, is given equivalent weighting as "era-appropriate" elements added to the game world for Rockstar to poke fun at, and therefore another false (and damaging) equivalence. 
The ambivalent inclusion of these elements in the games raises more questions than it answers. To what extent are we supposed to take these design and narrative choices as a valid critique or satire of American colonialism and historic white supremacy when other kinds of narratives of "progress" and "conquest" are exactly the kind of paratextual narrative Rockstar use to sell their games and developer brand? And indeed, if they were not included to create space for critical reflection on such issues, why are they included at all, and why were attempts to historicize the games as "truthful" made in the first place?

\section{Conclusion: The Outlaw Brand's “Frontier" Narrative(s)}

The way that companies like Rockstar seek to define the narrative of the past through their games, just as they aim to control the narrative of their own brand history and development, requires attention. These narratives, especially where they seek to deploy discourses of "progress" and "improvement" while making claims about historical "authenticity," deserve and require our scrutiny to critically unpack the ideological assumptions that linger just below the surface. In doing so, and as I have sought to argue elsewhere, we should be wary of attempting to separate analysis of paratextual framing from textual content, because it so often casts a different, harsher light on the potential ideological resonance games may contain (Wright, Rockstar Games; Wright, "Promotional Context").

The Rockstar-authored narratives of American Western history found in RDR and RDR2 are deeply informed by notions of "progress" as they are linked to the Frontier myth and the civilization and savagery binary. These themes are used both to provide wider narrative texture and as a useful moral disengagement factor (see Hartmann and Vorderer; Hartmann) to portray certain characters as evil, threatening antagonists, and therefore justify the ludonarrative imperative to fight and/or eliminate them, or satirize their beliefs as idiotic, despite being historical. This usually involves those characters who represent American institutions of law and governance, and otherwise the violence of modernizing "civilization."

But it is difficult to view these interactions as offering a sustained critique of the implicitly white supremacist underpinnings of this discourse. Deeply reliant on simplified (though pervasive) mythical dichotomies, Rockstar's politics often read as hopelessly muddled. Any attempt at offering "critique" is tarnished by a stringent adherence to specific requirements of the Rockstar brand: to tell stories in which white men are the ultimate victims of modern American "progress," and that the company is pushing new "frontiers" of game development. Indeed, in many ways this promotional and branding frame undermines narrative and gameplay attempts to be "critical" of American greed and progress, given the ways that the developer is otherwise deeply imbricated in these wider, historically rooted structures of capitalist exploitation.

These tensions make the Red Dead franchise, like many contemporary historical video games, conflicted in their possible meanings. On the one hand, Rockstar as a company do not bear the full brunt of responsibility for the way that video games occupy dubious ideological positions-they are merely capitalizing on a wider capitalistic, postmodern recycling of images so common to the game and entertainment industries. But on the other hand, it is difficult to argue that what we find in these games is a truly critical dealing with troublesome elements of America's past. Yet the choice to include 
them is political (even if unconscious), just like the choice to rely on implicitly colonialist narratives of progress, conquest, and frontier spirit to sell them. While the games industry has long wanted to have it both ways in its use of irony and critique, as critics we should continually try and point out the ways in which this leaves a true promise of "progress" in historical game creation unfulfilled.

\section{BIBLIOGRAPHY}

@RockstarGames. "RED DEAD REDEMPTION 2 is coming to PC November 5th.” Twitter, 4 October 2019, 3:35pm, https://twitter.com/rockstargames/status/1180129407710715905. Accessed 12 May 2020.

Almahr, Hussain. “Analyzing the Historical Context of The Last Of Us Part II's

Violence." Unwinnable. 2018. https://unwinnable.com/2018/10/18/analyzing-the-historicalcontext-of-the-last-of-us-part-iis-violence/. Accessed 12 May 2020.

Anderson, Carol. White Rage: The Unspoken Truth of our Racial Divide. Bloomsbury, 2017.

Blake, John. “The New Threat: 'Racism Without Racists.”' CNN, 27 November 2014, https:// edition.cnn.com/2014/11/26/us/ferguson-racism-or-racial-bias/index.html. Accessed 12 May 2020.

Bird, Ashlee. “The Mechanical Machinations of Manifest Destiny: Red Dead Redemption 2's Revisionist Western Ruse". Red Dead Redemption: History, Myth and Violence in the Video Game West, edited by John Wills and Esther Wright, $\mathrm{U}$ of Oklahoma $\mathrm{P}$, forthcoming.

Byrd, Jodi A. "Red Dead Conventions: American Indian Transgeneric Fictions." The Oxford Handbook of Indigenous American Literature, edited by James H. Cox and Daniel Heath Justice, Oxford UP, 2014, pp. 344-58.

Chapman, Adam. Digital Games as History: How Videogames Represent the Past and Offer Access to Historical Practice. Routledge, 2016.

Coldewey, Devin. "Red Dead Redemption 2 Sees Rockstar Raising the Bar for Realism in OpenWorld Games.” TechCrunch, 9 Aug. 2018, https://techcrunch.com/2018/08/09/red-deadredemption-2-sees-rockstar-raising-the-bar-for-realism-in-open-world-games/. Accessed 3 Feb. 2021.

Cowen, Nick. "Red Dead Redemption 2 Exclusive Gameplay Preview: Riding with the Dutch van Der Linde Gang." The Telegraph, 4 May 2018, https://www.telegraph.co.uk/gaming/features/reddead-redemption-2-exclusive-gameplay-preview-riding-dutch/. Accessed 3 Feb. 2021.

-----. “Red Dead Redemption Video Game Preview." The Telegraph, 5 June 2009, https:// www.telegraph.co.uk/technology/video-games/5453573/Red-Dead-Redemption-video-gamepreview.html. Accessed 3 Feb. 2021.

Deloria, Philip J. Playing Indian. Yale UP, 1998.

Dippie, Brian W. The Vanishing American: White Attitudes and U.S. Indian Policy. U of Kansas P, 1982. 
Dyer-Witheford, Nick, and Greig De Peuter. Games of Empire: Global Capitalism and Video Games. U of Minnesota P, 2009.

Freeman, Will. “Here's Why Red Dead Redemption 2 Looks and Feels Its Best on PC.” PCGamesN, 1 Nov. 2019, https://www.pcgamesn.com/red-dead-redemption-2/pc-gameplay?amp. Accessed 3 Feb. 2021.

Fuchs, Michael, et al. "Playing Serial Imperialists: The Failed Promises of BioWare's Video Game Adventures." The Journal of Popular Culture, vol. 51, no. 6, 2018, pp. 1476-99.

Hammar, Emil Lundedal. "Producing \& Exploiting the Cultural Memory of the American West: Imperialism, Gender, \& Labor at Rockstar." Red Dead Redemption: History, Myth and Violence in the Video Game West, edited by John Wills and Esther Wright, U of Oklahoma P, forthcoming.

Hartmann, Tilo. “The 'Moral Disengagement in Violent Videogames' Model." Game Studies, vol. 17, no. 2, 2017, http://gamestudies.org/1702/articles/hartmann. Accessed 3 Feb. 2021.

Hartmann, Tilo, and Peter Vorderer. "It's Okay to Shoot a Character: Moral Disengagement in Violent Video Games.” Journal of Communication, vol. 60, no. 1, Mar. 2010, pp. 94-119.

Hooton, Christopher. "Red Dead Redemption 2 First Play Review: This Game Is Alive - Here's What We Learned After A Couple Of Hours Spent With It.” The Independent, 21 Sept. 2018, https:// www.independent.co.uk/life-style/gadgets-and-tech/gaming/...ameplay-xbox-one-ps4-mapcharacters-story-graphics-a8546481.html. Accessed 3 Feb. 2021.

Humphreys, Sara. “Rejuvenating 'Eternal Inequality' on the Digital Frontiers of Red Dead Redemption.” Western American Literature, vol. 47, no. 2, 2012, pp. 200-15.

Keller, Alexandra. "Historical Discourse and American Identity in Westerns since the Reagan Administration." Film \& History, vol. 33, no. 1, 2003, pp. 47-54.

Kelly, Andy. “The Past, Present, and Future of Rockstar's World-Conquering Grand Theft Auto Online.” PC Gamer, 21 Nov. 2019, https://www.pcgamer.com/uk/the-past-present-and-future-ofrockstars-world-conquering-grand-theft-auto-online/. Accessed 3 Feb. 2021.

Kerr, Aphra. The Business and Culture of Digital Games: Gamework/Gameplay. SAGE, 2006.

Kline, Stephen, et al. Digital Play: The Interaction of Technology, Culture, and Marketing. McGillQueen's UP, 2003.

Kuenz, Jane. "The Cowboy Businessman and 'The Course of Empire': Owen Wister's 'The Virginian." Cultural Critique, vol. 48, 2001, pp. 98-128.

Lammes, Sybille. "Postcolonial Playgrounds: Games as Postcolonial Cultures.” Eludamos: Journal for Computer Game Culture, vol. 4, no. 1, 2010, pp. 1-6.

Limerick, Patricia Nelson. The Legacy of Conquest: The Unbroken Past of the American West. Norton, 1987.

Litherland, Benjamin. "Ludosity, Radical Contextualism, and a New Games History: Pleasure, Truth, and Deception in the Mid-20th-Century London Arcade." Games and Culture, 2019, pp. 1-21.

MacDonald, Keza. "Get Real! Behind the Scenes of Red Dead Redemption 2 - the Most Realistic Video Game Ever Made.” The Guardian, 24 Oct. 2018, https://amp.theguardian.com/games/2018/ oct/24/get-real-behind-the-scenes-of-red-dead-redemption-2-the-most-realistic-video-gameever-made?_-_twitter_impression=true. Accessed 2 Feb. 2021. 
McCaffrey, Ryan. “Red Dead Redemption 2's First 4 Hours: The 'Open World' Just Evolved.” IGN, 2 Oct. 2018, http://uk.ign.com/articles/2018/10/02/red-dead-redemption-2s-first-4-hours-theopen-world-just-evolved. Accessed 2 Feb. 2021.

McKeand, Kirk. "Red Dead Redemption 2 PC Preview - Photo Mode and Graphics Upgrades Make This the Definitive Version." VG24/7, 1 Nov. 2019, https://www.vg247.com/2019/11/01/red-deadredemption-2-pc-preview-photo-mode/amp/?__twitter_impression=true. Accessed 2 Feb. 2021.

Margini, Matt. Red Dead Redemption. Boss Fight Books, 2020.

Mukherjee, Souvik. Videogames and Postcolonialism: Empire Plays Back. Palgrave Macmillan, 2017.

Mukherjee, Souvik, and Emil Lundedal Hammar. "Introduction to the Special Issue on Postcolonial Perspectives in Game Studies." Open Library of Humanities, vol. 4, no. 2, 2018, pp. 1-14.

Murray, Soraya. "Horizons Already Here: Video Games and Landscape." Art Journal, vol. 79, no. 2, 2020, pp. 42-49.

-----. On Video Games: The Visual Politics of Race, Gender and Space. I.B. Tauris, 2018.

-----. "The Triumphal Procession." ROMchip: A Journal of Game Histories, vol. 1, no. 1, 2019, http:// www.romchip.org/index.php/romchip-journal/article/view/77. Accessed 3 Feb. 2021.

Nooney, Laine. "A Pedestal, a Table, a Love Letter: Archaeologies of Gender in Videogame History." Game Studies, vol. 13, no. 2, 2013, http://gamestudies.org/1302/articles/nooney. Accessed 3 Feb. 2021.

Rockstar Games. "L.A. Noire Honored as First Videogame to Make Official Selection of the Tribeca Film Festival." Rockstar Newswire, 29 Mar. 2011, https://www.rockstargames.com/newswire/ article/14861/la-noire-honored-as-first-videogame-to-make-official-selection-o.html. Accessed 3 Feb. 2021.

----. "New Inventions Sweep the Nation - Part One: Communication, Devices and More (The True West - History That Helped Inspire Red Dead Redemption)." Rockstar Newswire, 27 Apr. 2010, http://www.rockstargames.com/newswire/article/4241/new-inventions-sweep-the-nation-partone-communication-devices-a.html. Accessed 3 Feb. 2021.

-----. "Red Dead Redemption 2 for PC Now Available to Pre-Purchase via the Rockstar Games Launcher." Rockstar Newswire, 9 Oct. 2019, https://www.rockstargames.com/newswire/article/ 61159/Red-Dead-Redemption-2-For-PC-Now-Available-to-Pre-Purchase-via-the-Roc? utm_source=twitter\&utm_medium=social\&utm_campaign=rdr2pc-10092019\&utm_content=newswire. Accessed 3 Feb. 2021.

----- “The Brands of Red Dead Redemption.” Rockstar Newswire, 4 June 2010, https:// www.rockstargames.com/newswire/article/4801/the-brands-of-red-dead-redemption.html. Accessed 3 Feb. 2021.

-----. "The True West - History That Helped Inspire Red Dead Redemption. Bad Guys Gone Good...And Vice Versa - Part One: Frank James.” Rockstar Newswire, 27 Jan. 2010, http:// www.rockstargames.com/newswire/article/2511/the-true-west-history-that-helped-inspire-reddead-redemption-ba.html. Accessed 3 Feb. 2021.

----. “The True West - History That Inspired Red Dead Redemption: Patent Medicines, Drink and Drugs." Rockstar Newswire, 17 Sept. 2010, http://www.rockstargames.com/newswire/article/ 7081/the-true-west-history-that-inspired-red-dead-redemption-patent-m.html. Accessed 3 Feb. 2021. 
----. “Western Weaponry of the Early 20th Century (The True West - History That Helped Inspire Red Dead Redemption).” Rockstar Newswire, 4 June 2010, http://www.rockstargames.com/ newswire/article/5421/western-weaponry-of-the-early-20th-century-the-true-westhistory.html. Accessed 3 Feb. 2021.

Ryan, John. "Red Dead 2 on PC Looks Better Than Ever." IGN, 1 Nov. 2019, https://uk.ign.com/ articles/2019/11/01/red-dead-2-pc-hands-on-preview?sf111699744=1. Accessed 2 Feb. 2021.

Saini, Angela. Superior: The Return of Race Science. $4^{\text {th }}$ Estate, 2019.

Sarkar, Samit. "Red Dead Redemption 2 on PC Is Exactly What You Think It Is." Polygon, 1 Nov. 2019, https://www.polygon.com/platform/amp/2019/11/1/20942406/red-dead-redemption-2rdr2-pc-impressions. Accessed 2 Feb. 2021.

Schoppmeier, Sören. "Playing to Make America Great Again: Far Cry 5 and the Politics of Videogames in the Age of Trumpism." COPAS: Current Objectives of Postgraduate American Studies, vol. 20, no. 1, 2019, pp. 6-23.

Schreier, Jason. "Inside Rockstar Games' Culture of Crunch.” Kotaku, 23 Oct. 2018, https:// kotaku.com/inside-rockstar-games-culture-of-crunch-1829936466. Accessed 3 Feb. 2021.

Senior, Tom. "Red Dead Redemption 2 Looks Gorgeous on PC, but Mouse Controls Make It Special." PC Gamer, 1 Nov. 2019, https://www.pcgamer.com/amp/red-dead-redemption-2-looksgorgeous-on-pc-but-its-mouse-controls-that-make-it-special/?__twitter_impression=true. Accessed 3 Feb. 2021.

Serwer, Adam. "White Nationalism's Deep American Roots." The Atlantic, April 2019, https:// www.theatlantic.com/magazine/archive/2019/04/adam-serwer-madison-grant-whitenationalism/583258/. Accessed 1 Feb. 2021.

Slotkin, Richard. Gunfighter Nation: The Myth of the Frontier in Twentieth-Century America. U of Oklahoma P, 1992.

Take-Two Interactive Software. "Rockstar Games Breaks New Records with Grand Theft Auto V and Red Dead Redemption 2." Take-Two Interactive, 28 January 2020, https:// ir.take2games.com/news-releases/news-release-details/rockstar-games-breaks-new-recordsgrand-theft-auto-v-and-red?field_nir_news_date_value[min]=. Accessed 2 Feb. 2021.

Therrien, Carl. "Video Games Caught Up In History: Accessibility, Teleological Distortion, and Other Methodological Issues." Before the Crash: Early Video Game History, edited by Mark J.P. Wolf, Wayne State UP, 2012, pp. 9-29.

Tompkins, Jane. West of Everything: The Inner Life of Westerns. Oxford UP, 1992.

Trachtenberg, Alan. The Incorporation of America: Culture and Society in the Gilded Age. Hill \& Wang, 1982.

Uricchio, William. "Simulation, History, and Computer Games." Handbook of Computer Game Studies, edited by Joost Rassens and Jeffrey Goldstein, MIT Press, 2005, pp. 327-38.

Weber, Rachel. "Red Dead Redemption 2 Rides onto PC Packing New Gameplay and Graphics to Die For." Gamesradar, 1 Nov. 2019, https://www.gamesradar.com/red-dead-redemption-2-pchands-on-preview/? utm_content=bufferaab3c\&utm_medium=social\&utm_source=twitter.com\&utm_campaign=buffer_grtw. Accessed 1 Feb. 2021. 
Webster, Andrew. “Red Dead Redemption 2 Hands-on: Two Hours With Rockstar's Wild West Epic.” The Verge, 20 Sept. 2018, https://www.theverge.com/2018/9/20/17879658/red-deadredemption-2-hands-on-gameplay-preview-ps4-xbox. Accessed 1 Feb. 2021.

Wright, Esther. "Marketing Authenticity: Rockstar Games and the Use of Cinema in Video Game Promotion." Kinephanos: Journal of Media Studies and Popular Culture, vol. 7, no. 1, 2017, pp. 131-64.

-----. “On the Promotional Context of Historical Video Games.” Rethinking History, vol. 22, no. 4, 2018, pp. 598-608.

-----. Rockstar Games and American History. Doctoral Thesis. University of Warwick, 2019.

\section{NOTES}

1. For example, RDR's final act; $R D R 2$ 's lengthy epilogue, and the (admittedly optional) emphasis on doing "chores" around the Van Der Linde camp, and providing food, income, and provisions for the gang and its members.

2. See Emil Lundedal Hammar's forthcoming work for further exploration of Rockstar's labour practices.

3. See Ashlee Bird's forthcoming work for further examination of the Wapiti Reservation in RDR2.

4. This dialogue is taken from the sixth-act mission "Favored Sons."

5. See Schoppmeier for the way that other video games have reflected this desire to "take the country back" within the context of the contemporary American political moment under Donald Trump.

6. For example, RDR2 includes optional random encounters in which the player might stumble upon KKK rallies throughout the game world, and optional side missions such as "The Iniquities of History," involving Jeremiah Compson, a former slave catcher who asks the player to help him retrieve his prized possessions after the bank has taken his home from him-a ledger of "recovered" slaves being one of these items.

\section{ABSTRACTS}

In both popular and historiographical discussions of the nineteenth- and twentieth-century American West, and the successive waves of popular culture that have come to represent Westward expansion and colonization, there has been much negotiation and debate over the nature and meaning of "progress." Usually bound up with other loaded terms such as "civilization" (and its implicit antithesis, "savagery"), popular culture that falls under the broader umbrella of the Western genre has often used the idea of progress and development, from past to future, as a cornerstone of their stories and messages. This article uses game developer Rockstar Games and the company's popular and commercially successful Red Dead Redemption franchise (2010-2018) to examine how narratives of "progress" have been used by the company not only to create their own representations of US history but, moreover, to prop up the promotional discourses that the company uses to brand themselves and sell their products. Ultimately, this article explores the tensions between a company that claims to offer games that are both "authentic" and critical of turn-of-the-century US history and culture, yet which 
implicitly rely on the ideologies that accompany narratives of "progress" and "civilization," bound up as they are with the Frontier myth, white supremacy, and colonialism.

\section{INDEX}

Keywords: American West, Frontier Narrative, Red Dead Redemption, Rockstar Games, Marketing

\section{AUTHOR}

\section{ESTHER WRIGHT}

Esther Wright is Lecturer in Digital History at Cardiff University, where she researches and teaches historical video games and their paratextual surround. Her monograph, Rockstar Games and American History: Promotional Materials and the Construction of Authenticity, is forthcoming from De Gruyter in 2022. 